\title{
Multiobjective Location Model Design Based on Government Subsidy in the Recycling of CDW
}

\author{
Peihua Fu, Hongxuan Li, Xiaohua Wang, Juanjuan Luo, Sha-lei Zhan, and Chao Zuo \\ Logistics Management and Engineering, Zhejiang Gongshang University, Hangzhou 310018, China \\ Correspondence should be addressed to Chao Zuo; chaozuo1982@gmail.com
}

Received 17 June 2017; Accepted 10 October 2017; Published 8 November 2017

Academic Editor: Rita Gamberini

Copyright (C) 2017 Peihua Fu et al. This is an open access article distributed under the Creative Commons Attribution License, which permits unrestricted use, distribution, and reproduction in any medium, provided the original work is properly cited.

\begin{abstract}
With the generation of a large amount of construction and demolition waste (CDW), many scholars have recently paid more attention to the recycling of CDW. In this paper, we design a classification recycling method based on the degree of CDW availability in the recycling of CDW. Considering the important role of the government in reverse logistics, a model of reverse logistics network based on the trade-off between cost and recycling rate is put forward, which is subject to government subsidy. The model includes the location of classification processing center and ensures the best route of transportation. Then, the improved particle swarm optimization algorithm is applied to solve the model to get Pareto frontier by transforming it into a multiobjective integer-programming problem. As a case study, the results of the statistical modeling used in this study indicate the feasibility of the model. Finally, according to the sensitivity analysis of government's subsidy, we evaluate the effectiveness of this program and its applicability.
\end{abstract}

\section{Introduction}

1.1. Background and Motivation. The construction industry is a pillar industry of many countries especially for China, which produces a lot of waste while consuming large amounts of resources. CDW usually includes concrete, wood, metal, gypsum board, building materials packaging cartons, plastic, asphalt, and debris. Due to the complex composition of construction waste and random stacking, how to deal with the CDW has become an urgent problem for many countries. Many scholars have studied the negative impacts of CDW on the environment, economy, and society. And these negative impacts will cause a lot of obstacles to our environment. For example, CDW will take up many land resources for accumulation. Study has shown that 10,000 tons of construction waste occupied 0.067 hectares of land [1]. Under certain conditions, some of the organic material in CDW will be converted to acid and alkali substances and then will enter the soil and the atmosphere; thus the air and water would be polluted [2].

China, as a rising power, has attracted increasing attention from the world $[3,4]$. The rapidly growing economy has propelled the development of construction industry. As the accumulation of a large number of CDW caused serious pollution to the environment, the demand of recycling in
CDW has grown substantially. From Table 1 [1], we can see that, in any structure, CDW accounts for a large proportion in the purchase of materials. Table 2 [1] depicts the main proportion of the CDW in terms of buildings in Hong Kong; it can be found that most of the waste material can be reused. As presented in Tables 1 and 2, promoting the construction of waste recycling and comprehensive utilization of resources has become an imperative requirement to build a resourceefficient and environmentally friendly society.

The main challenge of various building materials and mixed emission of construction waste is how to recycle the useful materials from CDW. Reasonable classification recycling of CDW can effectively improve the waste utilization. Regarding the specific process in Figure 1, the classification process is mainly based on the availability of waste.

1.2. Related Work. In China, the recycling of CDW has captured a great amount of attention in recent decades. For example, Yuan and Shen [5] analyzed the recent research trends in CDW; the result showed that the CDW was explored more and more, especially in developing countries. Chen [1] presented different categories of CDW recycling machinery and strategies of waste processing. Strategies about converting CDW landfills into successful CDW recycling 


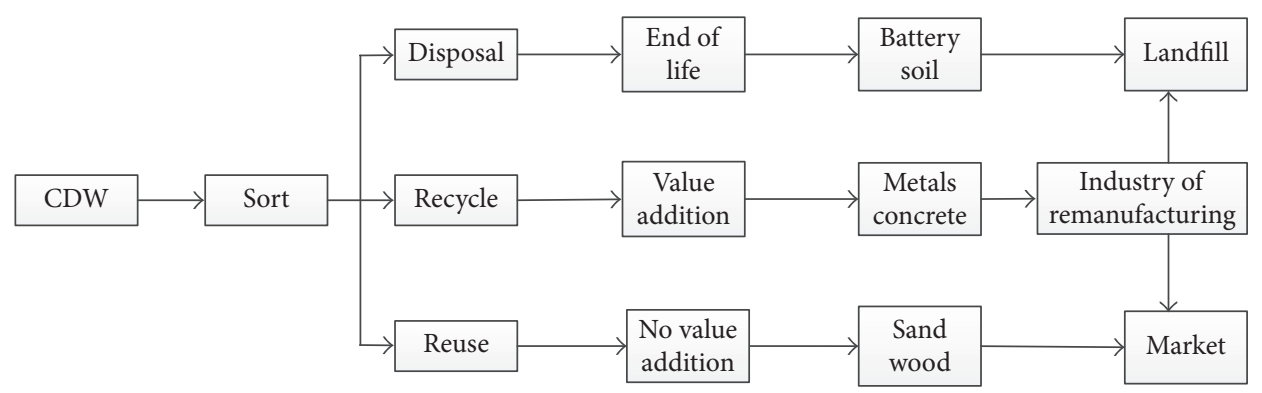

FIgURE 1: The flow chart of classification.

TABLE 1: New buildings produced waste in China, unit \%.

\begin{tabular}{|c|c|c|c|c|}
\hline Waste type & Brick structure & Framework & $\begin{array}{c}\text { Frame shear wall } \\
\text { structure }\end{array}$ & $\begin{array}{l}\text { The proportion of the main components } \\
\text { of CDW in the purchase of materials }\end{array}$ \\
\hline Bricks & $30-50$ & $15-30$ & $10-20$ & $3-12$ \\
\hline Mortar & $8-15$ & $10-20$ & $10-20$ & $5-10$ \\
\hline Concrete & $8-15$ & $15-30$ & $15-35$ & $1-4$ \\
\hline Packaging & 5-15 & $5-20$ & $10-20$ & $3-8$ \\
\hline Steel & $1-5$ & $2-5$ & $2-5$ & $2-8$ \\
\hline Wood & $1-5$ & $2-8$ & $2-8$ & $5-10$ \\
\hline Other & $10-20$ & $10-20$ & $10-20$ & - \\
\hline Total & 100 & 100 & 100 & - \\
\hline
\end{tabular}

TABLE 2: Composition of CDW in Hong Kong, unit \%.

\begin{tabular}{lcc}
\hline $\begin{array}{l}\text { Waste composition } \\
\text { ingredient }\end{array}$ & $\begin{array}{c}\text { Building demolition } \\
\text { waste }\end{array}$ & $\begin{array}{c}\text { Building } \\
\text { waste }\end{array}$ \\
\hline Concrete & 19.99 & 9.27 \\
Reinforced concrete & 33.11 & 8.25 \\
Soil & 11.91 & 30.55 \\
Rock & 6.83 & 9.47 \\
Asphalt & 1.61 & 0.13 \\
Bricks & 6.33 & 5.00 \\
Rubble & 4.95 & 14.13 \\
Wood & 7.15 & 10.53 \\
Glass & 0.20 & 0.56 \\
Sand & 1.44 & 1.70 \\
Metal & 3.41 & 4.36 \\
Other & 3.07 & 5.78 \\
\hline Total & 100 & 100 \\
\hline
\end{tabular}

operations are also examined. CDW recycling economics are presented to demonstrate the essential ingredients for successful operations. Abroad, the recycling of recycled sand from CDW was discussed [6]. The authors concentrated on a technique for producing high quality regenerated sand. A technique for producing high quality regenerated sand was proposed to improve the recovery technology. In this paper, Rao et al. [7] analyzed the situation of CDW recycling in the world and studied the role of government. Besides, the performance of recycling in the CDW recycle was also discussed. Some scholars studied the barriers to implementing of the reverse logistics of CDW $[8,9]$. Chileshe et al. [10] studied the relevant literatures and summed up the main barriers. These barriers include lack of recovery facilities and technical support; the limited liability for the usage of recycled materials; lack of legal and policy support; and higher recovery costs (labor costs, operational costs). Sangiorgi et al. [11] aimed at the application of construction waste in highway engineering, and the construction waste was in use instead of natural aggregate. As a consequence, the performance of the recovered aggregate was tested and the results showed that the recovery of the aggregate was good in the case of proper compaction and could show some positive self-cementation properties.

Mulder et al. [12] summed up the experience of reverse construction management for CDW in the Netherlands. A model of the recycling center for CDW was established by Nunes et al. [13], which focused on the Brazilian construction waste recycling center and introduced the concept of reverse logistics and reverse distribution channel network. Then the case of Brazilian CDW was well studied. Chileshe et al. [14] were meant to present a survey of barriers perception to implement reverse logistics (RL) practices in South Australian (SA) construction organizations. This study entitled "Designing for Reverse Logistics (DfRL) within the Building Life Cycle: Practices, Drivers and Barriers," which was examining the best practices and drivers that could be used as a "road map" for developing appropriate solutions for the successful implementation of RL. Sobotka and Czarnigowska 
[15] defined the concept of building-related reverse logistics and analyzed the factors of stimulation and regulation. In the end, this paper quoted an example of a reverse logistics model, which may be the basis for creating a decision support system.

The optimization of the location is an important part of reverse logistics network for the waste recycling. Kilic et al. [16] established a reverse logistics system for Turkey's WEEE. By mixing the integer linear programming model and taking into account the different collection rates, 10 scenarios were discussed. Different types of storage sites and recycling facilities were different in this model from existing research. In each case, the best location for storage and recycling facilities was available to meet the EU's minimum recovery requirements for each product category. Cruz-Rivera and Ertel [17] sought to describe the establishment of a closed loop supply chain of several features in Mexico. Consequently, the problem was resolved by reverse logistics and imitating the problem through the incapacitated facility. Alshamsi and Diabat [18] proposed a mixed integer linear programming (MILP) to solve the complex network configuration RL system, which determined the best choice of sites, the capacity of test center, and remanufacturing facility. According to the actual situation of the test, the results confirmed an important practical significance. Ramezani et al. [19] conducted a study on the logistics network design with a number of conflicting goals, such as cost/profit, resource balance, customer responsiveness, and quality. In the uncertain environment, a random multiobjective model was proposed, which included three kinds of forward directions in uncertain environment. The set of Pareto optimal solutions were obtained and the financial risks associated with them were calculated to demonstrate the trade-off between the targets. The results provided an important perspective for the development of decision-making processes.

As we all know, the government plays an important role in reverse logistics. Jia et al. [20] constructed a new model, where the proportion of waste recycling and reuse was lower. They described a penalty and subsidy mechanism in order to achieve subsidies to encourage the recycling and reuse of materials to improve it. Thus, the study concluded that some penalties and subsidy programs could effectively alleviate problems related to CDW management. Lakhan [21] explained the impact of urban cycling incentives on urban recovery and project costs in Ontario, Canada. The results of the statistical models used in this study indicated that there was no significant relationship between urban incentives, cycle rates, or project costs. Mitra and Webster [22] examined the effects of government subsidies as a means to promote remanufacturing activity; they found that the introduction of subsidies increased remanufacturing activity, and that the manufacturer's profits generally decreased while the remanufacturer's profits increased when $100 \%$ of the subsidy went to the remanufacturer.

In this paper, we analyze the recycling of CDW and establish a reverse logistics network model of construction waste based on trade-offs between the cost and recycling rate [23] according to the level of utilization of CDW, which is subject to government intervention.

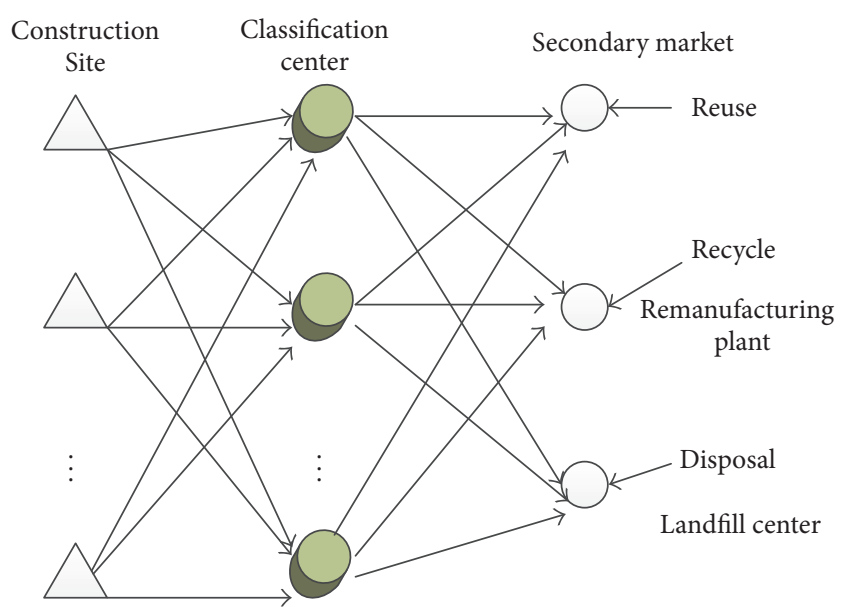

FIGURE 2: Framework of reverse logistics for construction waste recycling.

1.3. Contributions. The above observations motivate us to design an efficient reverse logistics network for CDW. In this paper, we make several contributions. We describe the level of utilization of CDW and discuss related problems of RL models. After that, we establish a model of reverse logistics network, which is subject to government subsidy.

This paper is organized as follows. The system model is described in Section 2, and the numerical simulation is presented in Section 3. Finally, we conclude this article in Section 4.

\section{Model Establishment}

2.1. Problem Statement. We consider a CDW recycling model as shown in Figure 1, where the construction waste is classified into three types: reuse, recycle, and disposal according to the availability. The simplified model is presented in Figure 2.

There are some sites of CDW, where CDW generated is transported to the center of classification and processing by vehicles in one cycle. In the center of classification and processing, CDW is classified and transported respectively to different processing sites according to the classification. Location-routing problem of construction waste includes determination of the location and number of the centers of classification and processing as shown in Figure 3. On the other hand, it also includes solving the path problem of waste vehicles in one cycle.

\subsection{Mathematical Formulation}

2.2.1. Model Assumptions. Before establishing the model, in order to facilitate the analysis and description of the problem, some assumptions are made in this paper, which are given as follows:

(1) All recycling activities in this paper are conducted in the model.

(2) Each alternative classification processing center is known. 


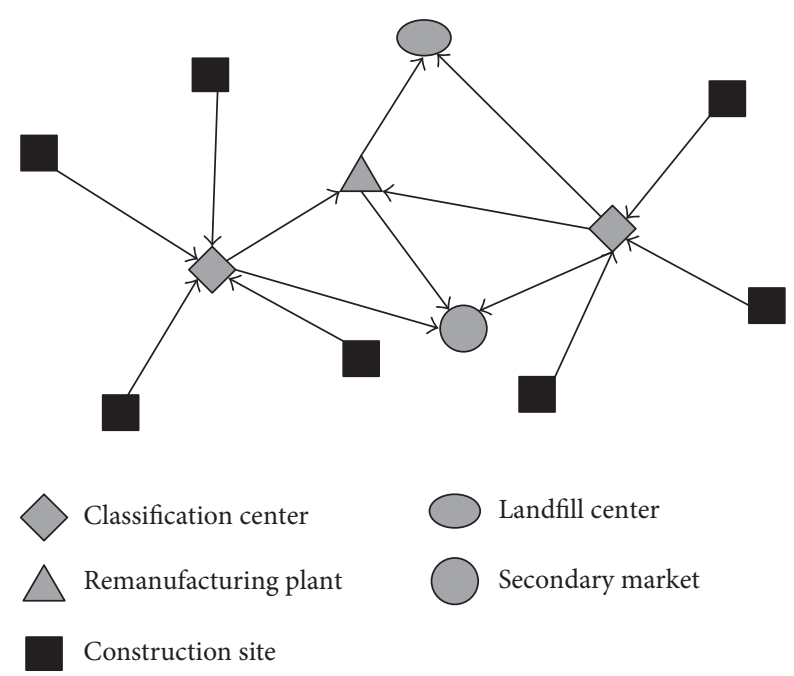

FigURE 3: Network structure of reverse logistics for construction waste recycling.

(3) The system relies on existing secondary market, remanufacturing plant, no longer considers their construction costs, and only considers their operating costs.

(4) The transportation costs of construction waste are linearly related to the distance.

\subsubsection{Notation}

\section{Superscript}

$A$ : The construction waste site

$B$ : Classification center

$C$ : Secondary market

$D$ : Remanufacturing plant

$E$ : Landfill center

$j \in J$ : The generation point of construction waste

$k \in K$ : The center of classification

$l \in L$ : Secondary market

$m \in M$ : Remanufacturing plant

$n \in N$ : The center of landfill

\section{Others}

$R_{1}, R_{2}$ : The points of rewards and punishment of recovery rate formulated by government

$a_{1}, a_{2}$ : The coefficients of rewards and punishment formulated by government

$\zeta$ : The actual recovery of the system

$\tau$ : Remanufacturing rate of remanufacturing plant which is subject to normal distribution

$\alpha$ : Unit disposal costs of classification processing center, yuan/ton $\beta$ : Unit disposal costs of remanufacturing processing center, yuan/ton

$M^{K}$ : The maximum processing capacity of the sorting center

$A_{j}(x, y)$ : The construction waste site $j \in J$

$O$ : The distance between the two places, the unit (circle $/ \mathrm{km} / \mathrm{ton}$ )

\section{General Parameters}

$u_{j k}^{a b}$ : The quantity of construction waste transported from the construction waste site to the classification center during a period, tons

$u_{k n}^{b e}$ : The quantity of construction wastes transported from the classification center to the landfill center during a period, tons

$u_{k m}^{b d}$ : The quantity of renewable resources transported from classification center to the remanufacturing plant during a period, tons

$u_{k l}^{b c}$ : The quantity of renewable resources transported from classification center to the secondary market during a period, tons

$u_{m l}^{d c}$ : The quantity of renewable resources transported from the remanufacturing plant to the secondary market during a period, tons

$u_{m n}^{d e}$ : The quantity of wastes transported from the remanufacturing plant to the center of landfill during a period, tons

$\chi_{k}^{b d}:$ The weight ratio of construction waste from the classification center to the remanufacturing plant

$\chi_{k}^{b c}$ : The weight ratio of construction waste from the classification center to the secondary market

$\chi_{k}^{b e}$ : The weight ratio of construction waste from the classification center to the landfill center

\section{Construction Cost}

$F_{k}^{b}$ : Construction costs of classification center $F_{n}^{e}$ : Construction costs of landfill processing center

Decision variables are defined as follows:

$B_{k}$

$= \begin{cases}1 & \text { If the classification centers are built in alternative } k \\ 0 & \text { otherwise. }\end{cases}$

2.2.3. Model Establishment. The model has two objective functions and seven constraints.

(1) Objective Functions. The proposed model has economic and recycling rate objective functions.

Recycling rate objective functions are

$$
\min \mu_{1}=1-\frac{\left(\sum_{k} u_{k l}^{b c}+\sum_{k} u_{m l}^{d c}\right)}{\sum_{j} u_{j k}^{a b}} .
$$


The overall costs of the collection point consider the construction costs of processing center, storage fees, handling fees, transportation costs, and government subsidies. As the government vigorously promotes the recycling of used products, government subsidies is a function of recycling rate. Hence, economic costs can be expressed as

$$
\begin{aligned}
& \min \mu_{2}=\left(\sum_{k} F_{k}^{b}+\sum_{n} F_{n}^{e}+\alpha \sum_{k} u_{j k}^{a b}+\beta \sum_{k} \sum_{m} u_{k m}^{b d}\right. \\
& +\lambda u_{k n}^{b e}+\lambda u_{m n}^{d e}+\sum_{k} O u_{j k}^{a b} g+\sum_{k} O u_{k m}^{b d} g+\sum_{k} O u_{k n}^{b e} g \\
& \left.\quad+\sum_{k} O u_{k l}^{b c} g+O u_{m l}^{d c}+O_{m}^{n} u_{m n}^{d e} g\right) .
\end{aligned}
$$

The objective functions (2) and (3) represent the minimum proportion of disposal waste and the lowest total cost of the whole system.

Assume that the government imposes incentives on the recycling of CDW, and the government sets a recycling rate for the class recyclers and rewards the excess if the actual recycling rate of the classified recycler exceeds the government's recycling rate. Specific incentive measures are as follows.

$f(\zeta)$ is a subordinate government subsidy function, which is related to the recycling rate of the recovery point $\zeta$. When the recycling rate is less than the fixed number $R_{1}$, the government will give the enterprise a certain penalty for the classification and recovery enterprise; unit penalty is $a_{1}$. When the recovery rate is greater than the fixed rate, the government will give the enterprise certain reward; unit reward rate is $a_{2}$; that is,

$$
f(\zeta)= \begin{cases}a_{2}\left(R_{2}-\zeta\right) Q & \zeta<R_{2} \\ 0 & R_{2} \leq \zeta \leq R_{1} \\ a_{1}\left(\zeta-R_{1}\right) Q & \zeta>R_{1} .\end{cases}
$$

Considering the general situation, in the premise of $R_{1}, R_{2} \neq 0$, there are two kinds of decision-making situation: (1) when $R_{1}=R_{2}>0$; at that time, there are both incentives and punishments; (2) when $R_{1}>R_{2}>0$; at that time, there are three subsidies, incentives and punishment and neither incentive nor punishment. Second and third cases are to determine which measures have a better effect.

Therefore, under the government intervention, the objective function is as follows:

$$
\begin{aligned}
& \min \mu_{1}=1-\frac{\left(\sum_{k} u_{k l}^{b c}+\sum_{k} u_{m l}^{d c}\right)}{\sum_{j} u_{j k}^{a b}}=1-\zeta, \\
& \min \mu_{2}=\left(\sum_{k} F_{k}^{b}+\sum_{n} F_{n}^{e}+\alpha \sum_{k} u_{j k}^{a b}+\beta \sum_{k} \sum_{m} u_{k m}^{b d}\right. \\
& +\lambda u_{k n}^{b e}+\lambda u_{m n}^{d e}+\sum_{k} O u_{j k}^{a b} g+\sum_{k} O u_{k m}^{b d} g+\sum_{k} O u_{k n}^{b e} g \\
& \left.\quad+\sum_{k} O u_{k l}^{b c} g+O u_{m l}^{d c}+O_{m}^{n} u_{m n}^{d e} g\right)+f(\zeta) .
\end{aligned}
$$

(2) Constraints. The proposed model includes the following ten constraints.

S.T:

$$
\begin{aligned}
\sum_{j} u_{j k}^{a b} & =\sum_{k} u_{k m}^{b d}+\sum_{k} u_{k n}^{b e}+\sum_{k} u_{k l}^{b c} \quad j \in J \quad k \in K, \\
\sum_{k} u_{k m}^{b d} & =u_{m l}^{d c}+u_{m n}^{d e} \quad k \in K, \\
\chi_{k}^{b d} \times \sum_{j} u_{j k}^{a b} & =\sum_{k} u_{k l}^{b c} \quad k \in K, \\
\chi_{k}^{b c} \times \sum_{j} u_{j k}^{a b} & =\sum_{k} u_{k l}^{b c} \quad k \in K, \\
\chi_{k}^{b e} \times \sum_{j} u_{j k}^{a b} & =\sum_{k} u_{k n}^{b e} \quad k \in K .
\end{aligned}
$$

Capacity constraints:

$$
\begin{gathered}
\sum_{j} u_{j k}^{a b} \leq \sum_{k} F_{k} M^{E} \quad k \in K \\
F_{k} \in\{0,1\} .
\end{gathered}
$$

Constraints (6) and (7) represent the flow balance of the waste through the center of classification and processing and the manufacturers of building materials. Constraints (8), (9), and (10) indicate gravity constraint of the waste transported from classification center to the distributors of building materials, the manufacturers of building materials, and the center of landfill processing center. Constraints (11) indicate that the total amount of construction waste is less than or equal to the value of the processing power and decision variables of the center of classification and processing.

\section{Numerical Simulation}

3.1. Multiobjective Methodology. There are some methods existing to solve traditional multiobjective problems, such as weighting method where the weight between multipleobjective functions needs to be given by the decision-maker. Besides, the constraint method and max-min method are difficult to deal with because the dimension among multipleobjective functions is inconsistent. Thus, we choose the multiobjective particle swarm optimization (MOPSO) algorithm to solve the model $[24,25]$.

In order to solve the model by using particle swarm optimization algorithm, an improved multiobjective particle swarm optimization algorithm is designed for this model.

The specific steps of the improved MOPSO method are as follows:

(1) Initialize the particle. The initial position of the particle and the initial velocity $Y$ are generated by random method. The target vector corresponding to each particle is calculated, and the noninferior solution is added to the scale group $M=20$ of the external file group.

(2) Determine the initial $p$-best and initial $g$-best of the particle. 
TABLE 3: The coordinates of secondary market, remanufacturing plant, and landfill center.

\begin{tabular}{lcc}
\hline & Abscissa & Ordinate \\
\hline Secondary market & 35 & 85 \\
Remanufacturing plant & 70 & 38 \\
Landfill center & 20 & 37 \\
\hline
\end{tabular}

(3) To ensure that the particles are in the search space within the flight conditions, change the particle speed and location; adjust the particle $p$-best.

(4) According to the new noninferior solution to maintain external files, the formation of each particle at the same time, select $g$-best.

(5) If the termination condition is satisfied, stop the search; otherwise return to step (3).

3.2. Case Study. In this section, a numerical example is presented in order to demonstrate the validity of the presented model. Consider a reverse logistics network similar to the one depicted in Figure 1. In the reverse logistics of this case, there are 10 construction sites, and then they are transported to 5 alternative classification recycling centers. The production capacity and coordinates of the construction waste disposal sites are shown in Table 3 . The processing capacity and coordinates of the alternative classification processing centers are shown in Table 4 . In this case, there is only one secondary market, remanufacturing plant, and landfill center. Costs per ton of classification center, secondary market, and landfill center are 15, 50, and 8 (yuan/ton). The transportation rates between nodes is 3 (yuan/ton $/ \mathrm{km}$ ). The coordinates and cycle generation of the construction waste site are shown in Table 5. Other parameters are reported in Table 6.

The two objective functions of two single objective functions are solved by particle swarm optimization algorithm. The results are shown in Table 7.

By using multiobjective particle swarm algorithm to solve the above model, the optimal solution is shown in Figure 4.

The Pareto optimal solution based on the multiobjective particle swarm optimization algorithm can be seen from Figure 4. And the function of the Pareto frontier is the concave function, which can explain the validity of the model. According to the relationship between the recycling rate and the total cost, the decision-maker can choose the appropriate solution based on the original cost or the expected recycling rate.

3.3. Sensitivity Analysis. We discuss the second case when $R_{1}>R_{2}>0$. At that time, $R_{1}=80 \%, R_{2}=50 \%$, and there are three measures: punishment and no subsidies, subsidies and no punishment, and subsidies and punishment. The second and third cases are aimed at determining which measure has a better effect.

(1) Punishment and No Subsidies. The government does not meet the required recycling rate to give economic penalties, but the recycling of waste products is not motivated (positive

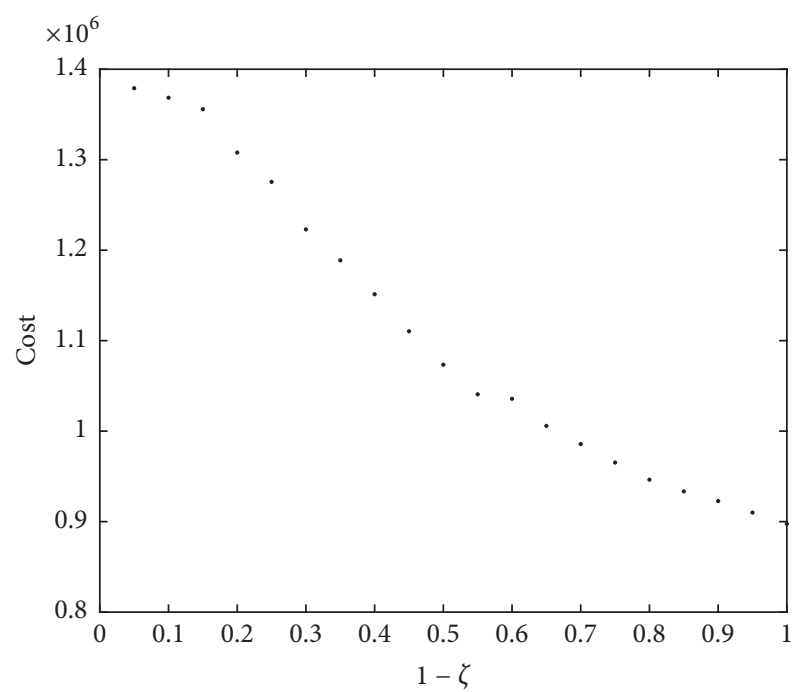

Figure 4: Pareto frontier of the model.

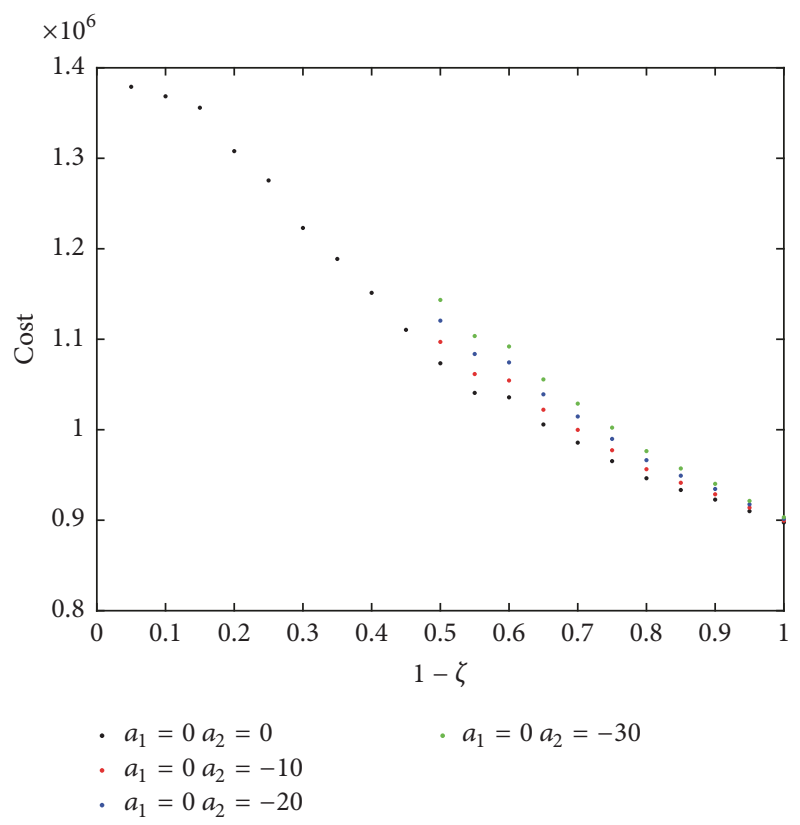

FIGURE 5: Pareto frontier of the model with punishments.

subsidies), $a_{1}=0, a_{2}<0$ (yuan). Pareto frontier of the model with punishments is as shown in Figure 5.

(2) Subsidies and No Punishment. The government subsidizes the discarded products that exceed the prescribed recovery rate and will not be punished for less than the prescribed recovery rate $\left(a_{1}>0, a_{2}=0\right)$. Pareto frontier of the model with subsidies is shown in Figure 6.

(3) Subsidies and Punishment. In this situation, the government will grant subsidies for the center whose waste exceeds the prescribed recovery rate and give punishment for those whose waste is less than the required rate $\left(a_{1}>0, a_{2}<0\right)$. 
TABLE 4: The coordinates, construction costs, and cyclic throughput of alternative classification center.

\begin{tabular}{lcccc}
\hline The center of classification & Abscissa & Ordinate & Construction cost (yuan) & Cyclic throughput (tons) \\
\hline 1 & 76 & 12 & 86000 & 900 \\
2 & 71 & 16 & 95000 & 1000 \\
3 & 65 & 66 & 101000 & 1000 \\
4 & 45 & 68 & 120000 & 1200 \\
5 & 49 & 27 & 97000 & 900 \\
\hline
\end{tabular}

TABLE 5: The coordinates and cycle generation of the construction waste site.

\begin{tabular}{lccc}
\hline $\begin{array}{l}\text { The construction } \\
\text { waste site }\end{array}$ & Abscissa & Ordinate & Output (tons) \\
\hline 1 & 92 & 19 & 328 \\
2 & 22 & 47 & 235 \\
3 & 51 & 59 & 224 \\
4 & 89 & 92 & 166 \\
5 & 55 & 76 & 205 \\
6 & 14 & 76 & 362 \\
7 & 26 & 57 & 400 \\
8 & 84 & 7 & 280 \\
9 & 82 & 53 & 191 \\
10 & 93 & 94 & 161 \\
\hline
\end{tabular}

TABLE 6: Transportation proportions.

\begin{tabular}{lc}
\hline$\chi_{k}^{p a}$ & $0 \%$ \\
$\chi_{k}^{p b}$ & $95 \%$ \\
$\chi_{k}^{p z}$ & $5 \%$ \\
\hline
\end{tabular}

Pareto frontier of the model with subsidies and punishments is as shown in Figure 7.

From the above analysis, we know that the government adjusts the reverse logistics of CDW by subsidizing this market. When the government faces the choice of incentive and punishment measures, the calculation results show that the incentive subsidy is more meaningful, especially when the system profitability is weak; giving appropriate incentives can help enterprises take the initiative to invest. However, the government as a reverse logistics participant also hopes that, through the minimum subsidy cost, enterprises can enhance its profitability through their own management and technology upgrading in order to achieve a virtuous cycle of CDW.

\section{Conclusion}

The Location-Routing Problem has become the key of the optimization of reverse logistics network, but there is little research on trade-offs between the cost and recycling rate. This paper studies the problem about the design of reverse logistics network and establishes a mixed integerprogramming model with considering the cost and recycling

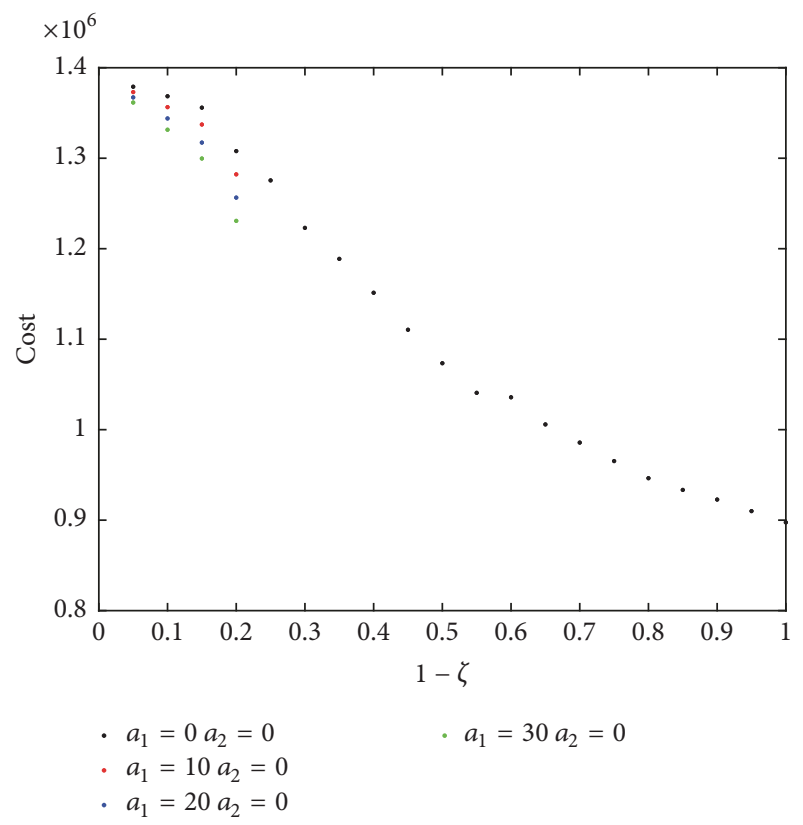

FIGURE 6: Pareto frontier of the model with subsidies.

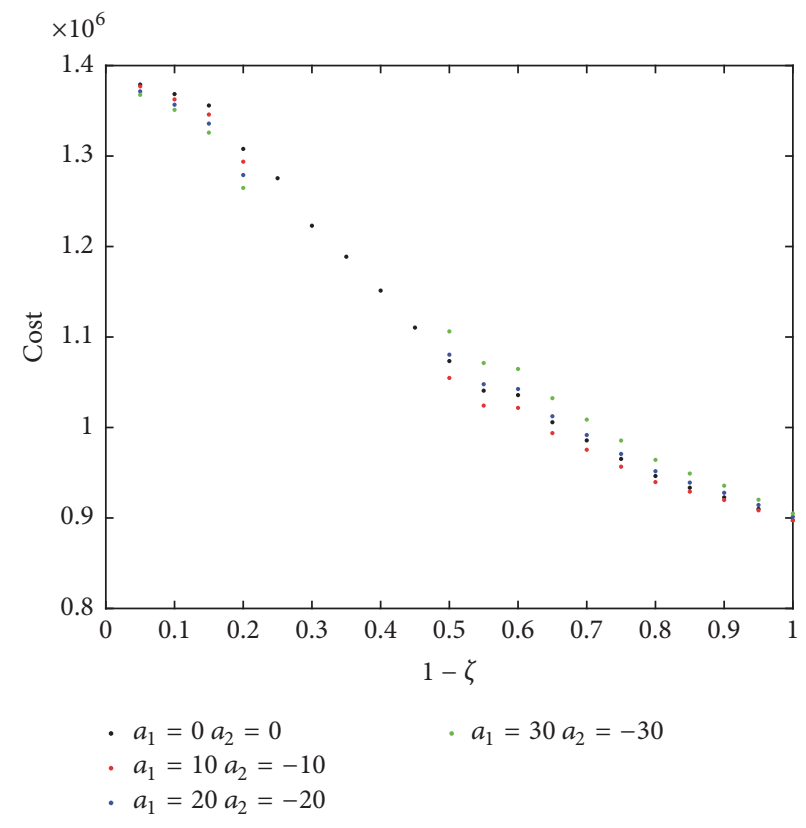

FIGURE 7: Pareto frontier of the model with subsidies and punishments. 
TABLE 7: Optimal solution of single objective function.

\begin{tabular}{|c|c|c|c|c|}
\hline $\begin{array}{l}\text { Objective } \\
\text { function }\end{array}$ & $\begin{array}{l}\text { The center of Classification } \\
\text { and recycling }\end{array}$ & Whether it is elected & Recycling rate & Costs (yuan) \\
\hline \multirow{5}{*}{$\mu_{1}$} & 1 & Yes & \multirow{5}{*}{$100 \%$} & \multirow{5}{*}{896500} \\
\hline & 2 & No & & \\
\hline & 3 & Yes & & \\
\hline & 4 & Yes & & \\
\hline & 5 & Yes & & \\
\hline \multirow{5}{*}{$\mu_{2}$} & 1 & Yes & \multirow{5}{*}{$5 \%$} & \multirow{5}{*}{1368500} \\
\hline & 2 & No & & \\
\hline & 3 & Yes & & \\
\hline & 4 & Yes & & \\
\hline & 5 & Yes & & \\
\hline
\end{tabular}

rate, which can be solved by using the multiobjective particle swarm optimization algorithm. By adding the government subsidies to the relevant factors of the total cost, the model is closer to the actual situation, and the multiobjective particle swarm optimization algorithm is used to optimize the model. Finally, the simulation and calculation of the model and the algorithm are carried out by the example.

Finally, the Pareto frontier is acquired, and the function of the Pareto frontier is the concave function. Thus, it can easily explain the validity of the model and provide the theoretical support for enterprises and government decision-makers to implement the reverse logistics scheme of construction waste. Through the sensitivity analysis, the positive subsidy can promote the development of reverse logistics, and the comparison between the algorithm and other algorithms such as genetic algorithm will be further studied.

\section{Conflicts of Interest}

The authors declare no conflicts of interest.

\section{Acknowledgments}

This work is supported by the Science and Technology Project of Zhejiang Province (no. 2017C31069, 2016C33172), the Natural Science the National Natural Science Foundation of China (no. 71603237), and Key Program of Natural Science Foundation of Zhejiang Province (no. LZ14G020001).

\section{References}

[1] Z. C. Chen, "Control and analysis on environmental object of construction project," Journal of Chongqing Jianzhu University, vol. 24, no. 2, pp. 93-96, 2002.

[2] E. K. Lauritzen, "Emergency construction waste management," Safety Science, vol. 30, no. 1-2, pp. 45-53, 1998.

[3] W. Liu, G. Hu, L. Tang, and Y. Wang, "China's global growth in social science research: uncovering evidence from bibliometric analyses of SSCI publications (1978-2013)," Journal of Informetrics, vol. 9, no. 3, pp. 555-569, 2015.

[4] C. S. Poon, A. T. W. Yu, and L. H. Ng, "On-site sorting of construction and demolition waste in Hong Kong," Resources, Conservation \& Recycling, vol. 32, no. 2, pp. 157-172, 2001.
[5] H. Yuan and L. Shen, "Trend of the research on construction and demolition waste management," Waste Management, vol. 31, no. 4, pp. 670-679, 2011.

[6] C. Ulsen, H. Kahn, G. Hawlitschek, E. A. Masini, S. C. Angulo, and V. M. John, "Production of recycled sand from construction and demolition waste," Construction and Building Materials, vol. 40, pp. 1168-1173, 2013.

[7] A. Rao, K. N. Jha, and S. Misra, "Use of aggregates from recycled construction and demolition waste in concrete," Resources, Conservation \& Recycling, vol. 50, no. 1, pp. 71-81, 2007.

[8] F. Schultmann and N. Sunke, "Energy-oriented deconstruction and recovery planning," Building Research and Information, vol. 35, no. 6, pp. 602-615, 2007.

[9] A. Chini and R. Buck, "Barriers for deconstruction and reuse/recycling of construction materials in USA," in Barriers for Deconstruction and Reuse/Recycling of Construction Materials, vol. 115, 2014.

[10] N. Chileshe, R. Rameezdeen, and M. R. Hosseini, "Barriers to implementing reverse logistics in South Australian construction organisations," Supply Chain Management Review, vol. 20, no. 2, pp. 179-204, 2015.

[11] C. Sangiorgi, C. Lantieri, and G. Dondi, "Construction and demolition waste recycling: an application for road construction," International Journal of Pavement Engineering, vol. 16, no. 6, pp. 530-537, 2015.

[12] E. Mulder, T. P. R. de Jong, and L. Feenstra, "Closed cycle construction: an integrated process for the separation and reuse of C\&D waste," Waste Management, vol. 27, no. 10, pp. 14081415, 2007.

[13] K. R. A. Nunes, C. F. Mahler, and R. A. Valle, "Reverse logistics in the Brazilian construction industry," Journal of Environmental Management, vol. 90, no. 12, pp. 3717-3720, 2009.

[14] N. Chileshe, R. Rameezdeen, M. R. Hosseini, S. Lehmann, and C. Udeaja, "Analysis of reverse logistics implementation practices by South Australian construction organisations," International Journal of Operations and Production Management, vol. 36, no. 3, pp. 332-356, 2016.

[15] A. Sobotka and A. Czarnigowska, "Analysis of supply system models for planning construction project logistics," Journal of Civil Engineering and Management, vol. 11, no. 1, pp. 73-82, 2005.

[16] H. S. Kilic, U. Cebeci, and M. B. Ayhan, "Reverse logistics system design for the waste of electrical and electronic equipment 
(WEEE) in Turkey," Resources, Conservation \& Recycling, vol. 95, no. 1, pp. 120-132, 2015.

[17] R. Cruz-Rivera and J. Ertel, "Reverse logistics network design for the collection of end-of-life vehicles in Mexico," European Journal of Operational Research, vol. 196, no. 3, pp. 930-939, 2009.

[18] A. Alshamsi and A. Diabat, "A reverse logistics network design," Journal of Manufacturing Systems, vol. 37, no. 3, pp. 589-598, 2015.

[19] M. Ramezani, M. Bashiri, and R. Tavakkoli-Moghaddam, "A new multi-objective stochastic model for a forward/reverse logistic network design with responsiveness and quality level," Applied Mathematical Modelling: Simulation and Computation for Engineering and Environmental Systems, vol. 37, no. 1-2, pp. 328-344, 2013.

[20] S. Jia, G. Yan, A. Shen, and J. Zheng, "Dynamic simulation analysis of a construction and demolition waste management model under penalty and subsidy mechanisms," Journal of Cleaner Production, vol. 147, pp. 531-545, 2017.

[21] C. Lakhan, "The relationship between municipal waste diversion incentivization and recycling system performance," Resources, Conservation \& Recycling, vol. 106, pp. 68-77, 2016.

[22] S. Mitra and S. Webster, "Competition in remanufacturing and the effects of government subsidies," International Journal of Production Economics, vol. 111, no. 2, pp. 287-298, 2008.

[23] Y. Hotta, C. Visvanathan, and M. Kojima, "Recycling rate and target setting: challenges for standardized measurement," Journal of Material Cycles and Waste Management, vol. 18, no. 1, pp. 14-21, 2016.

[24] H. Yapicioglu, A. E. Smith, and G. Dozier, "Solving the semidesirable facility location problem using bi-objective particle swarm," European Journal of Operational Research, vol. 177, no. 2, pp. 733-749, 2006.

[25] S. L. Ho, S. Yang, G. Ni, E. W. C. Lo, and H. C. Wong, "A particle swarm optimization-based method for multiobjective design optimizations," IEEE Transactions on Magnetics, vol. 41, no. 5, pp. 1756-1759, 2005. 


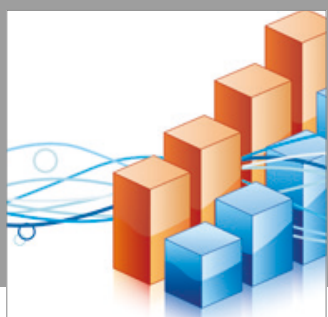

Advances in

Operations Research

vatersals

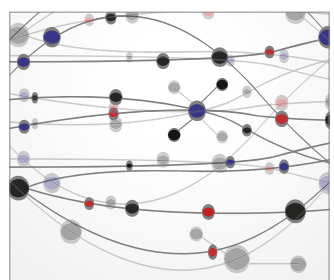

\section{The Scientific} World Journal
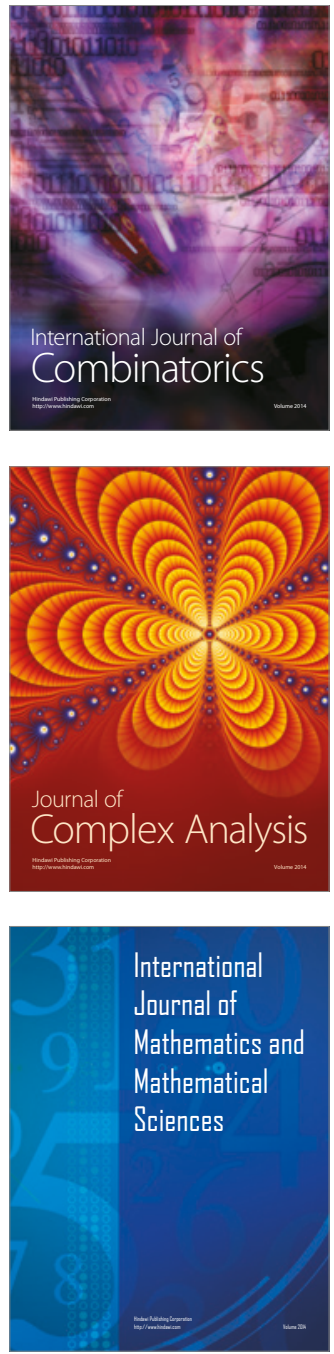
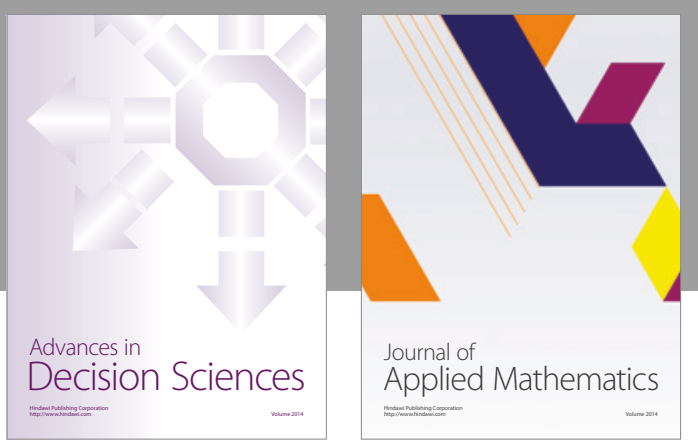

Algebra

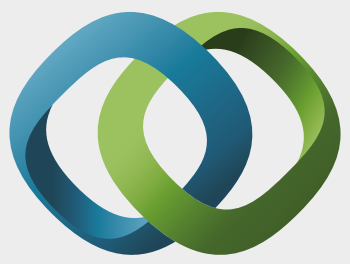

\section{Hindawi}

Submit your manuscripts at

https://www.hindawi.com
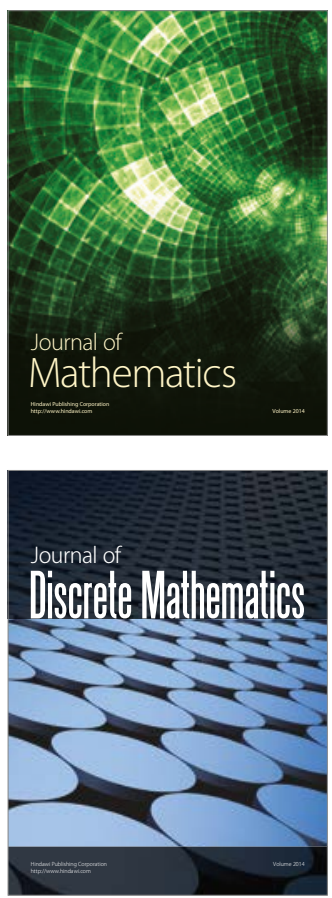

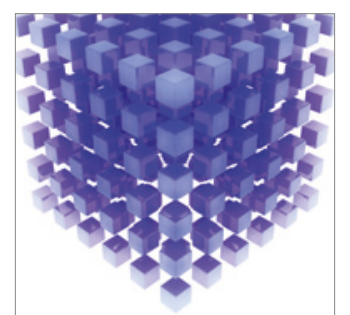

Mathematical Problems in Engineering
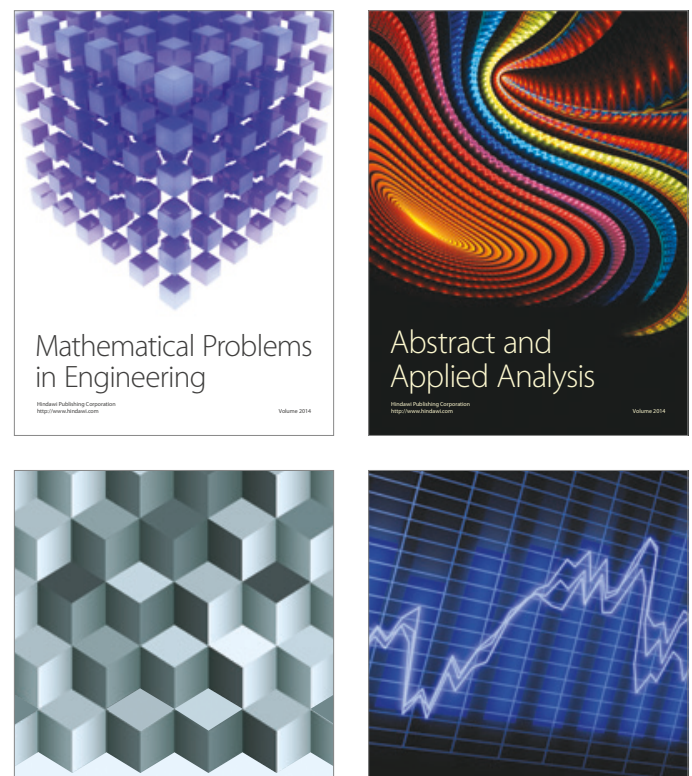

Journal of

Function Spaces

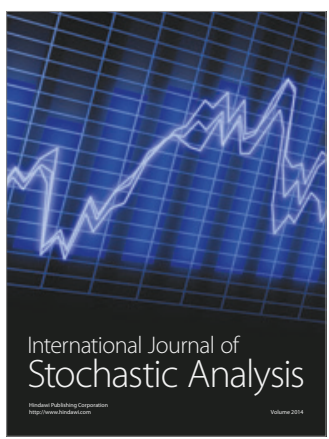

Probability and Statistics
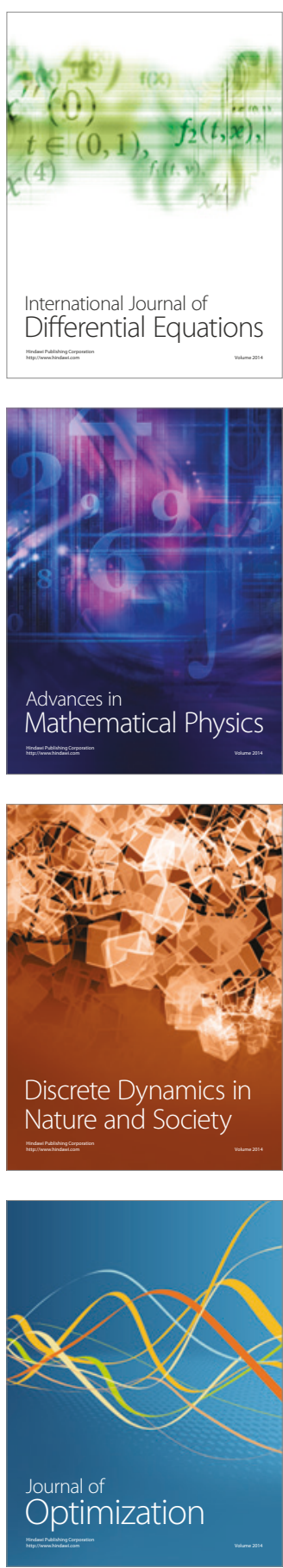